\title{
A Method for Tribological Measurements of Coated Abrasives using a Rheometer
}

\author{
Andreas Gammelgård ${ }^{1} \cdot$ Jessica Tuuf ${ }^{2}(1) \cdot$ Anders Strand $^{1} \cdot$ Mats Sundell $^{1} \cdot$ Margareta Björklund-Sänkiaho² $^{2}$
}

Received: 26 November 2020 / Accepted: 16 March 2021 / Published online: 9 April 2021

(c) The Author(s) 2021

\begin{abstract}
Coated abrasives (sandpaper) are imperative in various industrial areas, including the automotive and the metal industry. An exact outcome is often highly appreciated in abrasion processes, which means that the wear process must be precisely controlled. In this paper, a new method for analyzing the grinding process of coated abrasives is proposed. In order to study the grinding properties of sandpaper, a tribology cell was connected to a rheometer. The experiments consisted of unlubricated (dry) steel balls-on-disc experiments on coated abrasive with aluminum oxide grains. The friction and wear data showed that the rheometer equipped with a tribology cell can be used to measure different tribological parameters, such as the friction coefficient and the Gap. The wear process was investigated over a range of abrasive grain sizes $(9-40 \mu \mathrm{m})$ and a variety of different loads $(1-10 \mathrm{~N})$. Results from these experiments showed that the abrasive wear increased with increasing particle size and normal load. Hence, it is proposed that this method is a reliable approach for investigating the wear process of coated abrasives.
\end{abstract}

Keywords Coated abrasives $\cdot$ Rheometer $\cdot$ Tribology cell $\cdot$ Wear $\cdot$ Coefficient of friction $\cdot$ Gap

\section{Introduction}

Grinding materials, including coated abrasives (sandpaper), have gained a lot of interest in recent years due to their increased utilization in various fields. Generally, the purpose of grinding processes is to remove material from a surface or to give the surface a unique structure. Hence, coated abrasives are of utmost importance in furniture manufacturing applications [1], in the automotive industry [2], in glass polishing applications [3], and for processing of metal surfaces $[4,5]$. Because the requirements of the abrasives differ between these distinct industrial areas, the abrasives consist of different components. Normally, the coated abrasives consist of a backing (e.g. paper, fiber or cloth), a size coat (an adhesive bond), an abrasive material (grains), and additional components important for enhancing the abrasive function

Jessica Tuuf

jetuuf@abo.fi

Mirka Ltd, Pensalavägen 210, 66850 Jeppo, Finland

2 Faculty of Science and Engineering, Energy Technology, Åbo Akademi University, Strandgatan 2, 65100 Vasa, Finland of the material (Fig. 1), Mirka Ltd. (2009). Constructions of abrasives, unpublished manuscript.

There are several grinding materials that can be utilized as abrasives, however, the two most commonly used grain types found in sandpaper consist of aluminum oxide $\left(\mathrm{Al}_{2} \mathrm{O}_{3}\right)$ or silicon carbide $(\mathrm{SiC})$ [6-8]. Variations in the material morphology and the surface structure will have a large impact on the performance and the wear dynamics of the abrasive, which has also previously been demonstrated $[8$, 9]. Results from these published studies suggest that for example the grain size of the abrasives has a large effect on the wear rate, with a diminished wear rate below a certain particle diameter. To investigate the phenomena in these areas, the science of tribology can be used.

Tribology is the science of studying interacting surfaces in relative motion (friction, lubrication, and wear) and the characterization of system properties, such as the abrasive wear process. In tribological studies, the experiments are generally performed with tribometers with different types of setup devices, for example pin-on-disc, ball-on-disc and the ball-cratering (when an aqueous slurry of abrasive particles is analyzed) [6,10-13]. With the help of these conventional tools, information about the wear process will be obtained, and insights into important parameters, such as the wear 


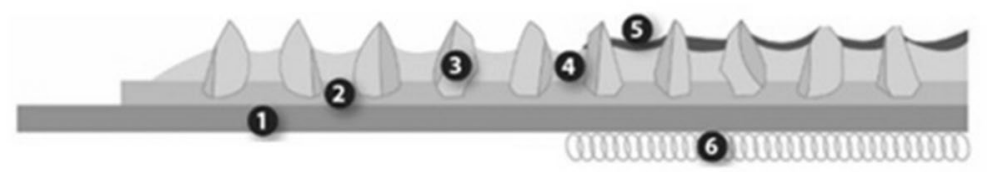

Fig. 1 Schematic picture of different layers in coated abrasives. The drawing depicts: 1 . the backing (e.g. paper, cloth or fabric) 2 . the make coat, important for attaching the grains 3 . the grains 4 . the

coefficient $(k)$, the wear rate $(Q)$, and the friction coefficient $(\mu)$, will be acquired. The importance of a precise grinding mechanism with an accurate and predetermined outcome is of utmost importance. Especially in the industrial sector, it is extremely crucial that the coated abrasives have a uniform and excellent quality. Hence, it is essential to have appropriate analyzing tools for both the abrasives and the workpiece. The grinded surface area can be analyzed with different methods, such as scanning electron microscopy (SEM), energy dispersive spectrometry, optical microscopy and X-ray diffraction $[5,10,13,14]$. Various traditional gravimetric approaches can also be conducted to identify the wear mechanism; by weighing materials before and after the wear test, the abrasive loss can be calculated and used as a means of wear characterization [15]. Precise methods for evaluating and defining the grinding tool itself, for example the coated abrasive, are also preferred. For this, SEM is regularly applied $[9,11]$, but also different surface topography studies have been employed, for example using 3D white light interferometer [4] or 3D modelling [16]. The surface of the grinding material is so complex in structure and in appearance that an exact analysis of the abrasion material itself is very difficult. In industrial applications, empirical studies are occasionally utilized on coated abrasives. This means that both visual inspection of the abrasives and previous experience within the field of grinding, will be of importance. Even though there already exist several methods for studying the wear mechanism, new reliable and inexpensive methods are needed.

The abrasive wear mechanism between two surfaces is very complex. Yet, the wear process has been described several times and is usually divided into two major groups: the two-body abrasive wear and the three-body abrasive wear, see, e.g. [17]. In the two-body abrasive wear, abrasive particles are attached to one body, while the second softer one slides over it. In three-body abrasive wear, particles from the softer grinded surface or the harder coated abrasive, enter the tribo-system and interfere with the wear mechanism. However, others suggest that the twobody and three-body abrasive wear definitions are not the most accurate ones, and instead recommend definitions for the wear process as sliding abrasion and rolling abrasion [17]. Additionally, it was proposed in another study that size coat, necessary for fixing and binding the grains to the coating 5. stearate coating, with antistatic properties 6 . the fastening system, which is required for attaching the abrasive to a grinding machine

abrasion could be classified based on the severity of the wear [18]. Already in the 60's, abrasive wear under threebody conditions was studied [19]. It was demonstrated here that the wear rate is influenced by the grit size. This was later also confirmed by Misra and coworkers who showed that this critical particle diameter was $100 \mu \mathrm{m}$, in pin-ondisc-type two-body abrasion experiments on five different metal surfaces [20]. Various phenomena within the field of tribology, such as wear, friction and lubrication, are related to phenomena in rheology, which is the science of deformation and material flow of liquids and soft materials. One of the instrument that is used in rheology is called a rheometer. However, there are also many other types of instruments that can be used for rheological studies, e.g. viscometer, TAXT/Instron, CaBER and RVA. The rheometer serves in an extensive range of applications, especially in studies where measurements of different flowing materials and characterization of sample properties are required. Applications include food industry [21], dental research [22] and pharmaceutical industry [23]. There are several advantages with a rheometer; the instrument is equipped with an accurate speed and force control and several basic parameters such as normal force, torque and temperature can be controlled. These parameters are also applied in tribology, which allows for complementary rheological and tribological studies. In 2009, Heyer and Läuger developed a new tribometer device, consisting of a rheometer connected to a tribology cell [24]. The aim of this study was to describe the method and propose applications in which the new device could be utilized. The results showed that the rheo-tribometer can successfully be used when analyzing the tribological behavior of various greases, and it was concluded that it could be utilized for other applications, that it was not initially designed for. The research regarding the rheo-tribometer has been extended to other fields of samples and accessories and results from such studies show that the setup can be used on food samples [25], and also with different sorts of tribology cells [26]. Nowadays, there are commercial tribometers available, which can provide detailed information about friction mechanisms. However, tribometers tend to be expensive. In practice, a laboratory is often equipped with a rheometer, but not necessarily a tribometer. Hence, the advantage of using a 
rheometer equipped with a tribology cell is to reduce cost and to enable a broader utilization within several different disciplines.

To our knowledge, there has been no detailed investigation of coated abrasives using a rheo-tribometer. The wear process of different abrasives will vary extensively, and new tools are necessary to examine such a mechanism. Therefore, the aim of the present study was to develop a new analysis method for the wear behavior of abrasives, using a rheometer in conjunction with a balls-on-disc tribology cell. A great advantage of this type of tribology cell is the possibility to perform tribological measurements at precisely defined conditions to mimic as closely as possible the real conditions, with a much smaller and more manageable sample. Parameters, such as the friction coefficient and the Gap, can be obtained through this type of measurement.

\section{Materials and Methods}

\subsection{Materials}

The tribological behavior of abrasives was investigated by analyzing steel balls sliding against different coated abrasives. In this study, the coated abrasive was MI231A (Mirka Ltd, Jeppo, Finland), which had a semi-open grain distribution that resisted surface loading and produced consistently excellent surface scratch patterns during use. The five different abrasive types utilized were MI231A: P2500, P1200, $\mathrm{P} 800, \mathrm{P} 500$ and P360, which differ from each other in grain size $(9 \mu \mathrm{m} \rightarrow 40 \mu \mathrm{m})$. The grains where composed of aluminum oxide $\left(\mathrm{Al}_{2} \mathrm{O}_{3}\right)$, and the backing was made from a 5 MIL $(125 \mu \mathrm{m})$ thick Polyester film. The steel balls, measuring $6 \mathrm{~mm}$ in diameter, where manufactured from $100 \mathrm{Cr} 6$ (AISI 52,100) steel and had an average surface roughness $\left(R_{a}\right)$ of $0.02 \mu \mathrm{m}$ (RGP, Italy). The isopropanol used for cleaning the steel balls was of $99 \%$ purity, and was obtained from Absor Oy, Finland.

\subsection{Rheometer Setup and Abrasive Wear Experiments}

The wear tests were carried out using an Anton Paar MCR 302 rheometer (Austria), equipped with a tribology cell, model T-PID/44 (Anton Paar, Austria). Three steel balls were attached to the measuring shaft on an adjustable spring in the tribology cell (Fig. 2a). The steel balls in the measuring cell were tightened to $8 \mathrm{Nm}$. The test specimens consisted of three balls and one abrasive disc (Fig. 2b). The disc had a diameter of $50 \mathrm{~mm}$ and was cut out of a large coated abrasive jumbo reel. An experiment consisted of three steel balls and one abrasive disc and for each experiment new balls and discs were used. The experiments were repeated three times for each grain size. Five different coated abrasives were tested in this study and the coated abrasives were stored in a climatized room $\left(23^{\circ} \mathrm{C}, 50 \% \mathrm{RH}\right)$.

The normal load was set to $1-10 \mathrm{~N} \pm 0.2 \mathrm{~N}$ during the grinding procedure. The tribological measuring unit rotated constantly with $300 \mathrm{rpm}$. The duration of an experiment was $724 \mathrm{~s}$, which corresponded to a sliding distance of $500 \mathrm{~m}$. All experiments were performed at $22{ }^{\circ} \mathrm{C}$ and the temperature control was provided by a Peltier system (Julabo, Germany). Immediately before the experiments, the balls were rinsed with isopropanol to remove dirt and other organic substances from the surface. The last preparation was to measure and record the total weight of the three balls. This was repeated after the test to measure the mass loss (Mettler Toledo PB303-S/FACT, USA).

During the analyses, the measuring shaft was lowered to establish contact between the balls and the coated abrasive disc, as well as to apply the necessary normal force at the contact site. The measuring shaft was pressed down against the coated abrasive to reach the inserted normal

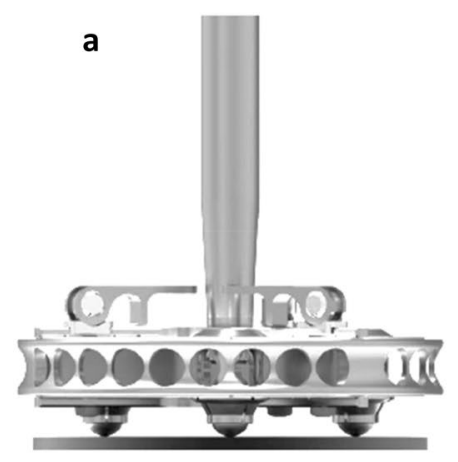

b

c
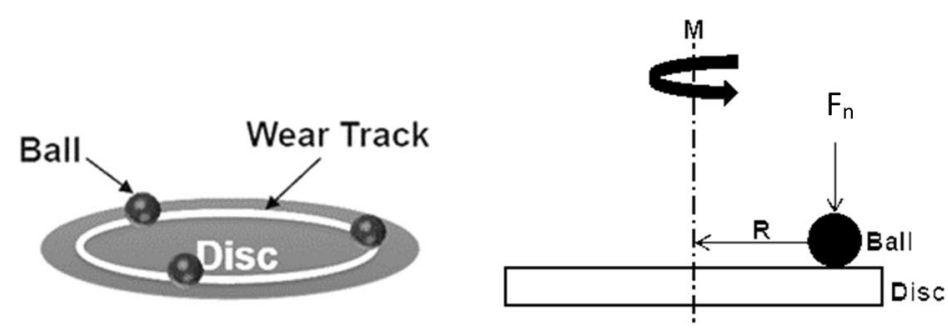

Fig. 2 The tribological cell unit. a Schematics of the T-PID/44 tribological measuring unit with three steel balls on a flexible spring. b The balls-on-disc setup, showing the wear process in the experiments. c The contact point between the sample ball and the coated sample disc, and the forces that occur ( $M$ Torque, $R$ radius, $F n$ tribological normal force) [27] 
force $2 \mathrm{~min}$ before the experiment started. The balls slid against the disc as the measuring shaft was rotating at a predetermined speed, mediated by the rheometer. The motor was operated using the RheoCompass computer software (Anton Paar, Austria), from where the test protocols and conditions were selected. In this investigation the sliding speed, time, moving profile, normal force and the test method were selected and modified in cooperation with Anton Paar. Post processing of data from RheoCompass was executed in MS Excel.

Wear tests, according to a standardized internal test method, were conducted with a special constructed test robot (Mirka Ltd, Finland). Steel specimens were grinded with the five different abrasive types. The specimens were weighed before and after abrasion to determine the total mass loss. The procedure was repeated three times.

\subsection{Data Analysis}

The following measurements and conversions were made. The steel balls, which were mounted to the measuring system shaft, were pressed onto the disc with a defined normal force $\left(F_{n}\right)$ (Fig. 2c). From the normal force the tribological normal force $\left(F_{n, \text { tribo }}\right)$ was calculated (Eq. 1):

$F_{n, t r i b o}=\frac{F_{n}}{3}$

The normal load was the force vertical to the friction surface of the disc. To maintain the speed, a specific torque $(M)$ was required, which was continuously measured by the rheometer. The frictional force $\left(F_{R}\right)$ was calculated according to (Eq. 2):

$F_{R}=\frac{M}{3 \times R}$

where $R$ is the radius from the center of the measuring shaft to the center of the balls.

The Coefficient of Friction (COF), often symbolized by the greek letter $\mu$, is calculated according to (Eq. 3):

$\mu=\frac{F_{R}}{F_{n, t r i b o}}$

The sliding distance $\left(s_{S}\right)$ was determined from the radius $(R)$ and displacement angle $(\phi)$ measured by the rheometer, and defined by (Eq. 4):

$s_{S}=\varphi \times R$

The total sliding distance $(S)$ was calculated from the revolution per minute (rpm), time in minutes $(t)$, the diameter from center to center of the balls in the measuring shaft $(D)$ and $\mathrm{Pi}(\pi)$, using (Eq. 5):
$S=\operatorname{rpm} \times t \times D \times \pi$

The Gap, which can be described as a quantitative wear indication in $\mathrm{mm}$, was examined in this study. The movement of the tribology cell head (upward or downward) was precisely controlled with an accuracy of $0.65 \mu \mathrm{m}$ by the stepper motor. This movement was responsible for the application of normal force at the contact interface.

\subsection{Microscopic Analysis}

After the initial COF experiment, the morphology of the worn abrasive disc (MI231A) was examined using a stereomicroscope (Nikon SMZ18, Japan) and a scanning electron microscope (Hitachi TM4000Plus, Japan).

\section{Results and Discussion}

\subsection{Coefficient of Friction}

Experiments, with a tribology cell connected to a rheometer, have successfully been conducted in several research areas. Goh and coworkers [28] have analyzed the food texture and the lubrication properties of emulsion systems using a tribology cell and they conclude that it can function as an appropriate investigating tool. Furthermore, dairy products in the form of semisolid or liquid [29], as well as various greases [30] can likewise be analyzed with success using the triborheometer system. However, tribological measurements with a rheometer on coated abrasives have until now not been tested. The results from the measured COF experiments performed with the rheo-tribometer, are depicted in Fig. 3.

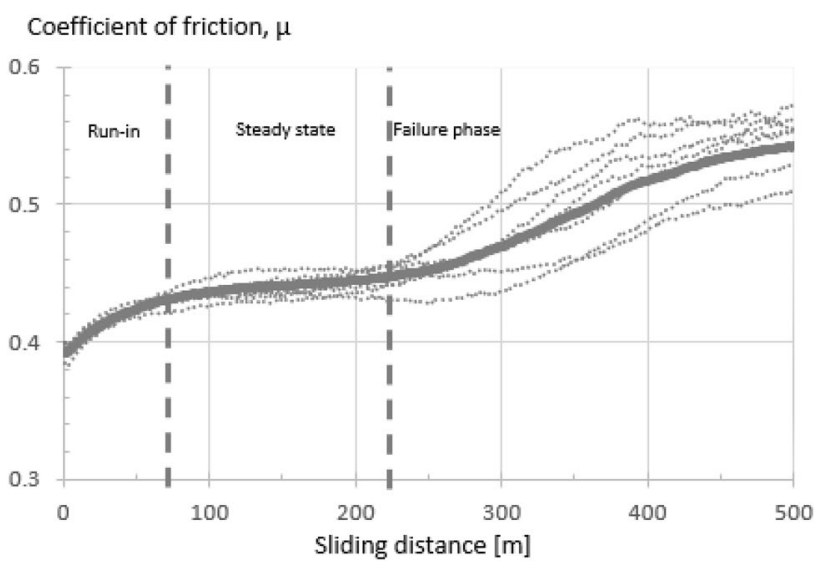

Fig. 3 Coefficient of friction experiments using the normal load $5 \mathrm{~N}$ and the speed $300 \mathrm{rpm}$ on the abrasive MI231A P800 $(20 \mu \mathrm{m})$. The calculated average is presented as a bold line and the seven independent experiments as dotted lines 
The initial experiments were performed to investigate the validity of the measurement technique. Because tribological systems can be very complex, it is demanding to obtain credible results from such experiments. Steel balls were grinded on MI231 A coated abrasive material and the COF was continuously measured and plotted versus the sliding distance. Seven separate tests with coated abrasive discs and new steel balls were performed. The friction coefficient was calculated and recorded every two seconds using the Anton Paar RheoCompass software. At the start of the test all friction curves presented similar friction behavior and the COF increased up to a sliding distance of about $70 \mathrm{~m}$ (Fig. 3). This behavior is typical in similar friction measurements and has been attributed to a "Run-in" phase [31]. During this phase the highest contact areas break loose and the surface topography changes. After the Run-in phase, the COF generally stabilized into a "Steady state" phase. In these experiments, the steady state lasted between a sliding distance of roughly 70 and $220 \mathrm{~m}$, and afterwards transcended into a so-called "Failure" phase. The Failure phase was recognized by increasing $\mathrm{COF}$, as well as more significant variations in the COF of the different samples after a sliding distance of $220 \mathrm{~m}$, as shown in Fig. 3. The presence of wear debris in the contact area between the coated abrasive and the steel balls will most likely make the tribological characteristics unstable, which has also previously been demonstrated [31]. An average COF was calculated from the different measurements, which is shown as the bold line in the graph. The average standard deviations were $1.0 \%$ during the Run-in phase, $1.5 \%$ during the Steady state phase, and 3.5\% during the Failure phase.

Results from previously published studies show that wear tests can vary greatly depending on different parameters in the tribological system [32, 33]. The COF factor of any wear test method is generally used to rank the grinding material composition, and therefore it is very important to validate the repeatability of the wear performance, determined through different test setups. According to [31] the interpretation of the $\mathrm{COF}$ values can be challenging. The
COF is very dependent of system parameters, therefore the interpretation of the results should always be done with caution. With these initial COF measurements, it was observed that the grinding procedure consisted of three distinct phases: Run-in, Steady state and Failure. The calculated standard deviations of the three different phases also show the increased uncertainty of COF measurements performed during the Failure phase. After the Failure phase, the friction coefficient might reach another steady state plateau before the coated abrasive is completely worn out according to literature [31]. Consequently, due to the high uncertainties within the Failure phase, the focus should not be on this phase, but rather on the Steady state phase when comparing the COF factor of different abrasive materials.

\subsection{Microscopic Analysis}

After the experiments shown in Fig. 3, the morphology of the worn abrasive (MI231A) was examined using a stereomicroscope and a scanning electron microscope. The objective was to investigate more closely the wear of the coated abrasive and to examine in detail why these three phases, and especially the Failure phase, occur during grinding. In this process, there are two phenomena that are of interest. Firstly, the appearance of wear debris in the system, and secondly the wear of the coated abrasive. An unused coated abrasive surface can be seen in Fig. 4a and is compared to Fig. $4 \mathrm{~b}$ which depicts the coated abrasives after the experiment. In Fig. 4b, the abrasive particles and the sandpaper are completely worn out. Figure $4 \mathrm{c}$ shows the wear path made by the tribology cell, which clearly is full of debris. These two phenomena explain why the coefficient of friction enters a Failure phase in the final step of the wear process. However, it must be pointed out that this grinding behavior with steel balls against abrasive material causes major forces upon the abrasive material, which does not happen in reallife applications.
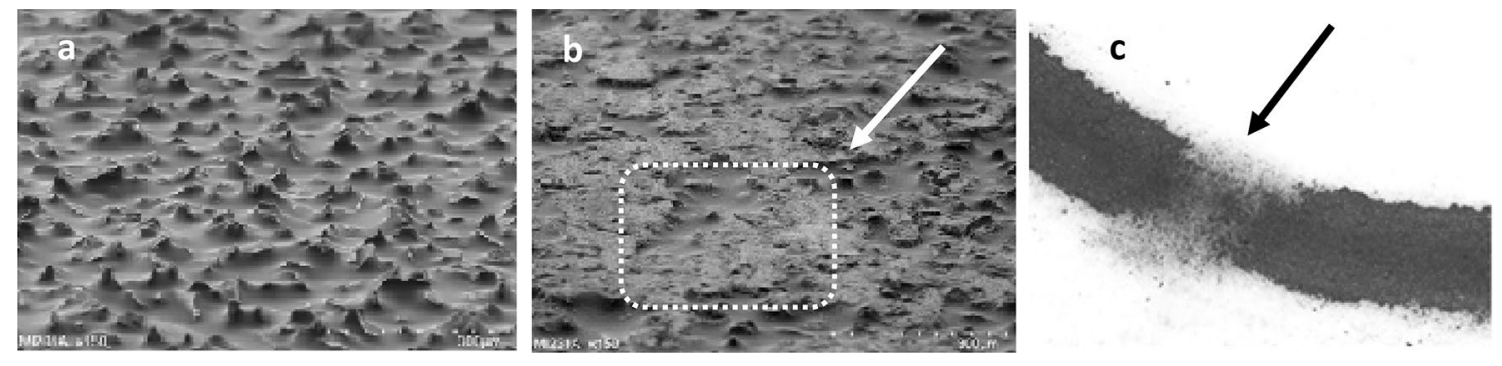

Fig. 4 a SEM picture in $\times 150$ magnification of unworn MI231A P800. b SEM picture of the same substrate as in Fig. 4a after the first experiment with a rheometer (normal force $5 \mathrm{~N}$, speed $300 \mathrm{rpm}$, sliding distance $500 \mathrm{~m}$ ). The arrow in the image shows the wear track from steel balls. $\mathbf{c}$ The same substrate as in (b) in $\times 3$ magnification using light microscopy. The wear track was gently brushed to visualize the amount of debris (black arrow) 


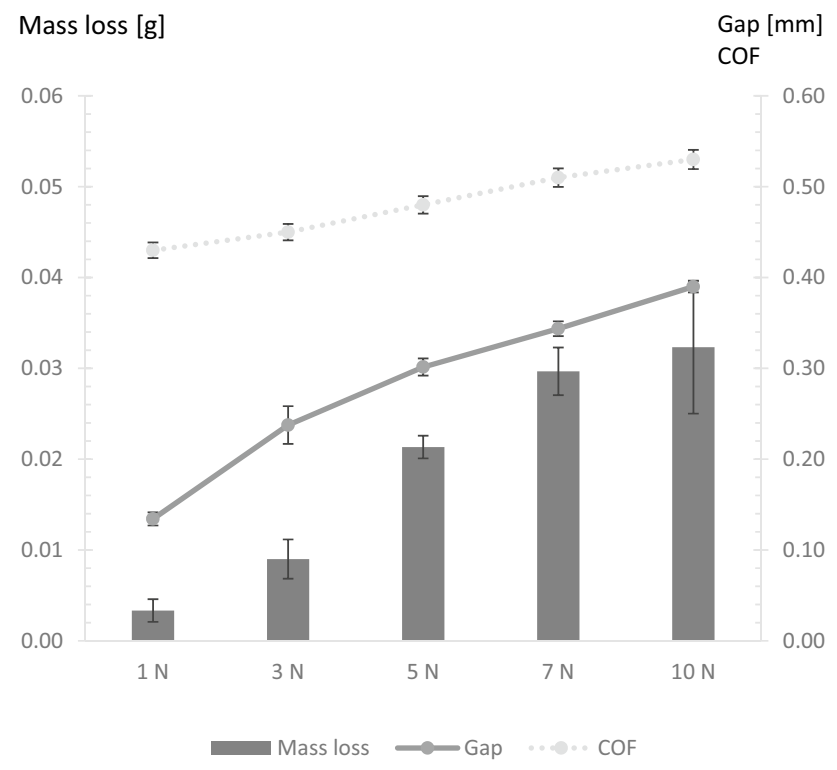

Fig. 5 Effect of normal load on the wear process. The mass loss (bars and scale to the left) and the Gap and (scale to the right) as a function of normal load using the abrasive MI231A P800 $(20 \mu \mathrm{m})$ on steel (speed $300 \mathrm{rpm}$, sliding distance $500 \mathrm{~m}$ ). The values are average of three independent experiments. The reported COF values were determined at steady state, an average from 70 to $220 \mathrm{~m}$ sliding distance (scale to the right)

\subsection{Effect of Normal Load on the Wear Mechanism}

To investigate whether different loads of pressure have an impact on the wear process in our experimental system, loads between 1 and $10 \mathrm{~N}$ were applied by the rheometer upon the abrasive material MI231A P800 $(20 \mu \mathrm{m})$. Figure 5 shows how different loads affected the mass loss of the steel balls and the Gap. The mass loss was calculated by weighing the balls before and after the wear test. The results clearly showed that the mass loss increased with increasing normal load, which indicated an enhanced wear. When analyzing the behavior of tribo-rheometer systems, the Gap is often noted as an important parameter in the analysis [34]. The Gap can be obtained directly from the RheoCompass computer software and could presumably be an indicator of abrasion. During the test when the tribology cell head is in contact with the interface, the head moves up and down to regulate the normal force to the set value. The Gap depends on the surface as well. On a hard (non-deflecting) surface, the Gap is roughly equivalent to wear depth, while on a soft surface, the Gap includes both wear and deflection.

The corresponding change in the Gap serves as an indicator of the transition and consequently, the wear performance. As more pressure is applied in the system, the Gap is enhanced, which corresponds well with its proposed role as an indicator of wear (Fig. 5). These results suggested that this test methodology is appropriate for testing the tribological characteristics of MI231A wear on steel.

The COF factor was examined at steady state, since this phase seemed to be the most reliable for comparing different coated abrasives (Fig. 3). The results show a slight increase in COF with increasing normal load.

Different factors are believed to contribute to the disparity of the wear mechanism. These include the shape, the size, and the chemical composition of the grains, but also the applied load in the grinding system is of great importance. Misra and Finnie showed that the wear of a specimen increased with increasing normal load during the abrasion process [35]. Furthermore, in a study examining the wear mechanism in two-body abrasion using a pin-on-disc test rig on silicon carbide paper, the wear rate was examined using three different sizes of grains; $5 \mu \mathrm{m}, 15.2 \mu \mathrm{m}$ and $82 \mu \mathrm{m}$ [6]. The results showed that the wear rate on steelpins is increased with all the grain sizes at a normal load from about $2 \mathrm{~N}$ up to $25 \mathrm{~N}$. In addition, normal load studies on other materials, for example on various aluminum alloys [33] or experiments performed at higher applied normal loads $(10-40 \mathrm{~N})[14,33]$, show that the wear increases with increasing normal load during the abrasive process.

\subsection{Effect of Grain Size}

Wear tests on different abrasives with various grit sizes were performed to determine whether the rheo-tribometer could be utilized to study this well-known size effect phenomenon. The results in Fig. 3 suggest that the Failure phase might not be the most optimal phase for analyzing the COF factor when comparing different coated abrasives with each other. However, to get a measurable mass loss from the steel balls in the rheo-tribometer, the tests proceeded to $500 \mathrm{~m}$.

It has previously been demonstrated that the size of the abrasive grains has an effect on the abrasion wear mechanism [20, 35-37]. Consequently, for small particle sizes an increase in the wear rate is observed as the particle size increases. However, after a critical grain size at about $100 \mu \mathrm{m}$, there is no further significant change in the wear rate [20]. Figure 6a shows experiments performed on coated abrasives with grain sizes between 9 and $40 \mu \mathrm{m}$.

To determine if the wear process in our tests could distinguish the known size effect, the abrasive mass loss was calculated by weighing the steel balls before and after the wear test. The mass loss of the steel balls, grinded by the different abrasives, is shown as grey bars in Fig. 6a. The results showed that the wear on steel is enhanced with increasing grain sizes, which was in agreement with previously reported findings [20, 36, 37]. The solid line in Fig. 6a, depicts the change in the Gap, measured by the RheoCompass software. The Gap increased with increasing grain size, which corresponds well with the proposed size effect when 
a

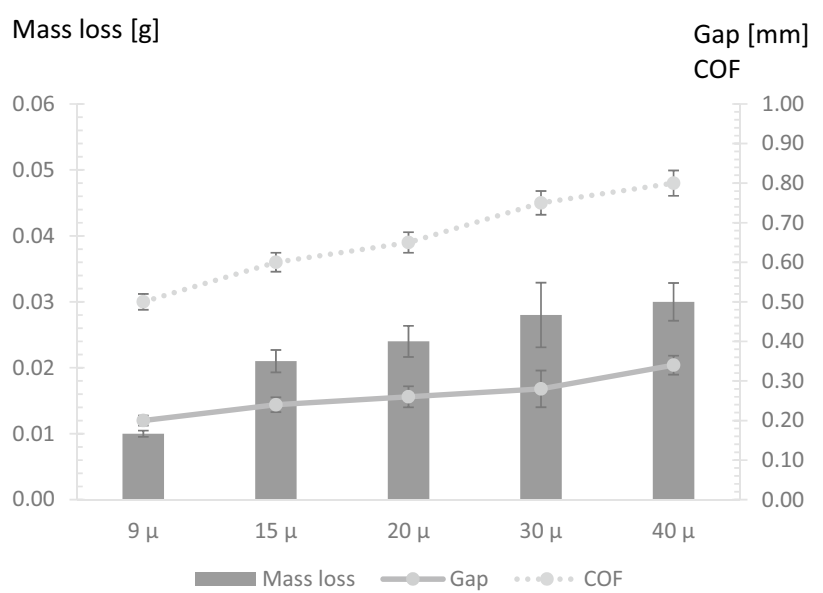

b

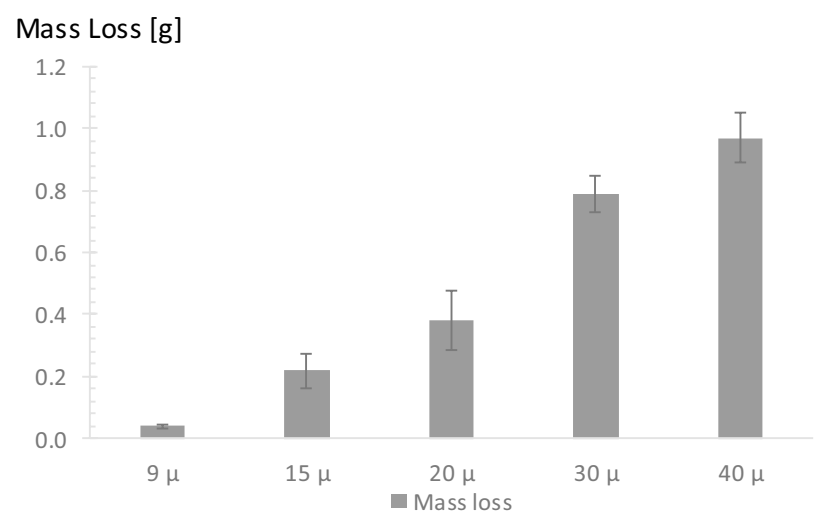

Fig. 6 Effect of grit size on the wear on steel. a The mass loss (bars, left) and the Gap (scale to the right) as a function of different grit sizes using the tribology cell together with a rheometer (normal force $5 \mathrm{~N}$, speed $300 \mathrm{rpm}$, sliding distance $500 \mathrm{~m}$ ). The reported COF values were determined at steady state, an average from 70 to $220 \mathrm{~m}$ sliding distance (scale to the right). $\mathbf{b}$ The mass loss as a function of different grit sizes using a Mirka internal test robot. Results are average of three independent experiments

using small grain sizes [20]. The COF factor measured at steady state also increases with increasing particle diameter. Hence, based on these results and the results in Fig. 5, it is concluded that the Gap can be used as a reliable indicator of the wear performance.

A separate validation experiment was performed to verify the behavior of the tested abrasive materials. To do this, a special constructed test robot, which is normally used at Mirka for internal wear tests, was utilized. According to an internal standard test method, the abrasion process of the abrasives on steel was analyzed. Before and after the wear tests the specimens were weighed and the mass loss was calculated. Figure $6 \mathrm{~b}$ depicts the sample loss as a function of grain size. Although the wear process is more effective in this test (more sample loss) in comparison to the tribology cell test method, the trend showed similar behavior, i.e. the wear increased with increasing grain size. These results further confirmed that the method for testing abrasives utilized in this study is working as proposed.

The accuracy of a test method is crucial. The standard deviation usually gives a good indication of the stability of the experimental setup. The results presented in Figs. 5 and 6 are based on three individual tests, and consequently show different accuracies. As can be seen in Fig. 5, the standard deviations between the triplicate samples within the gap experiment exhibit relatively small standard deviation values. One possible reason for this could be that the Gap was directly obtained from the software, and extra steps were therefore avoided. The standard deviations in the experiment with the mass loss of steel balls (Figs. 5 and 6) are relatively large between the triplicate samples. This might be due to the complexity of gravimetric analysis. Although weighing samples is an appropriate method in many cases, the number of steps and other insecurities in such experimental procedures can be of importance. The magnitude of the standard deviations could also be due to the placement of the abrasive specimens in the jumbo reel, which is a phenomenon that has also previously been observed [38].

\section{Conclusions}

In the present study, a tribology measurement system suitable for testing coated abrasives using a rheometer has been developed. Based on the tribological results it is concluded that:

(a) The rheo-tribometer setup works well and the grinding process correlates with internal testing methods. The results also show that the wear is increased with larger grain size, which is similar to the observations made in real-life applications.

(b) The fact that the grinding is divided into three distinct phases (Run-in, Steady state and Failure phase) correlated with previously published studies. These three distinct phases make it possible to compare different abrasive materials.

(c) The rheometer Gap can serve as an indicator of material wear and could replace weighing of sample balls.

(d) The wear performance depends strongly upon the degree of the normal force. The higher normal force between the mating surfaces, the greater is the wear, which is registered by the Gap.

(e) The effect of load, speed, distance, liquid, temperature, and the type of movement can easily be studied using the rheometer, and the measurements can be done 
under very controlled conditions compared to previously used equipment.

(f) Further investigations will be required to evaluate and optimize the testing parameters of this system for the purpose of measuring coated abrasive samples with different types of adhesives and grains.

\begin{abstract}
Acknowledgements We thank Florian Rummel from Anton Paar for comments on the manuscript. This research received funding from Högskolestiftelsen i Österbotten, Finland. The financial support is gratefully acknowledged.
\end{abstract}

Funding Open access funding provided by Abo Akademi University $(\mathrm{ABO})$. This research received funding from Högskolestiftelsen i Österbotten, Finland.

\section{Declarations}

Conflict of interest The authors declare that they have no known competing financial interests or personal relationships that could have appeared to influence the work reported in this paper.

Open Access This article is licensed under a Creative Commons Attribution 4.0 International License, which permits use, sharing, adaptation, distribution and reproduction in any medium or format, as long as you give appropriate credit to the original author(s) and the source, provide a link to the Creative Commons licence, and indicate if changes were made. The images or other third party material in this article are included in the article's Creative Commons licence, unless indicated otherwise in a credit line to the material. If material is not included in the article's Creative Commons licence and your intended use is not permitted by statutory regulation or exceeds the permitted use, you will need to obtain permission directly from the copyright holder. To view a copy of this licence, visit http://creativecommons.org/licenses/by/4.0/.

\section{References}

1. Ratnasingam, J., Reid, H.F., Perkins, M.C.: The productivity imperatives in coated abrasives - application in furniture manufacturing. Holz Als Roh- Werkst. 57, 117-120 (1999). https://doi. org/10.1007/s001070050026

2. ChandraYadaw, R., Singh, S.K., Chattopadhyaya, S., Kumar, S., Singh, R.C.: Comparative study of surface coating for automotive application-a review. Int. J. Appl. Eng. Res. 13, 17-22 (2018)

3. Enomoto, T., Satake, U., Fujita, T., Sugihara, T.: Spiral-structured fixed-abrasive pads for glass finishing. CIRP Ann. 62, 311-314 (2013). https://doi.org/10.1016/j.cirp.2013.03.011

4. Mezghani, S., El Mansori, M., Sura, E.: Wear mechanism maps for the belt finishing of steel and cast iron. Wear 267, 86-91 (2009). https://doi.org/10.1016/j.wear.2008.12.113

5. Xu, X., Yu, Y., Huang, H.: Mechanisms of abrasive wear in the grinding of titanium (TC4) and nickel (K417) alloys. Wear 255, 1421-1426 (2003). https://doi.org/10.1016/S0043-1648(03) 00163-7

6. De Pellegrin, D.V., Torrance, A.A., Haran, E.: Wear mechanisms and scale effects in two-body abrasion. Wear 266, 13-20 (2009). https://doi.org/10.1016/j.wear.2008.05.015
7. Mezghani, S., El Mansori, M.: Abrasiveness properties assessment of coated abrasives for precision belt grinding. Surf. Coat. Technol. 203, 786-789 (2008). https://doi.org/10.1016/j.surfcoat. 2008.08.058

8. Serpin, K., Mezghani, S., Mansori, M.E.: Wear study of structured coated belts in advanced abrasive belt finishing. Surf. Coat. Technol. 284, 365-376 (2015). https://doi.org/10.1016/j.surfcoat.2015. 10.040

9. Serpin, K., Mezghani, S., Mansori, M.E.: Multiscale assessment of structured coated abrasive grits in belt finishing process. Wear 332-333, 780-787 (2015). https://doi.org/10.1016/j.wear.2015. 01.054

10. Badisch, E., Mitterer, C.: Abrasive wear of high speed steels: Influence of abrasive particles and primary carbides on wear resistance. Tribol. Int. 36, 765-770 (2003). https://doi.org/10. 1016/S0301-679X(03)00058-6

11. Kaushik, NCh., Rao, R.N.: Effect of grit size on two body abrasive wear of Al 6082 hybrid composites produced by stir casting method. Tribol. Int. 102, 52-60 (2016). https://doi.org/10.1016/j. triboint.2016.05.015

12. Sedlaček, M., Podgornik, B., Vižintin, J.: Influence of surface preparation on roughness parameters, friction and wear. Wear $\mathbf{2 6 6}$, 482-487 (2009). https://doi.org/10.1016/j.wear.2008.04.017

13. Van Acker, K., Vanhoyweghen, D., Persoons, R., Vangrunderbeek, J.: Influence of tungsten carbide particle size and distribution on the wear resistance of laser clad WC/Ni coatings. Wear 258, 194-202 (2005). https://doi.org/10.1016/j.wear.2004.09.041

14. Singh, K., Khatirkar, R.K., Sapate, S.G.: Microstructure evolution and abrasive wear behavior of D2 steel. Wear 328-329, 206-216 (2015). https://doi.org/10.1016/j.wear.2015.02.019

15. Murthy, J.K.N., Venkataraman, B.: Abrasive wear behaviour of WC-CoCr and $\mathrm{Cr} 3 \mathrm{C} 2-20(\mathrm{NiCr})$ deposited by HVOF and detonation spray processes. Surf. Coat. Technol. 200, 2642-2652 (2006). https://doi.org/10.1016/j.surfcoat.2004.10.136

16. Arunachalam, A.P.S., Idapalapati, S.: Three-dimensional topography modelling of regular prismatic grain coated abrasive discs. Int. J. Adv. Manuf. Technol. 96, 3521-3532 (2018). https://doi. org/10.1007/s00170-018-1731-5

17. Hutchings, I., Shipway, P.: Wear by hard particles. In: Hutchings, I., Shipway, P. (eds.) Tribology, 2nd edn., pp. 165-236. Butterworth-Heinemann, Oxford (2017)

18. Gates, J.D.: Two-body and three-body abrasion: a critical discussion. Wear 214, 139-146 (1998). https://doi.org/10.1016/S00431648(97)00188-9

19. Rabinowicz, E., Dunn, L.A., Russell, P.G.: A study of abrasive wear under three-body conditions. Wear 4, 345-355 (1961). https://doi.org/10.1016/0043-1648(61)90002-3

20. Misra, A., Finnie, I.: On the size effect in abrasive and erosive wear. Wear 65, 359-373 (1981). https://doi.org/10.1016/00431648(81)90062-4

21. Tabilo-Munizaga, G., Barbosa-Cánovas, G.V.: Rheology for the food industry. J. Food Eng. 67, 147-156 (2005). https://doi.org/ 10.1016/j.jfoodeng.2004.05.062

22. Lee, I.B., Cho, B.H., Son, H.H., Um, C.M.: Rheological characterization of composites using a vertical oscillation rheometer. Dent. Mater. 23, 425-432 (2007). https://doi.org/10.1016/j.dental. 2006.02.013

23. Navaneethan, C.V., Missaghi, S., Fassihi, R.: Application of powder rheometer to determine powder flow properties and lubrication efficiency of pharmaceutical particulate systems. AAPS PharmSciTech 6, E398-E404 (2005). https://doi.org/10.1208/pt060349

24. Heyer, P., Läuger, J.: Correlation between friction and flow of lubricating greases in a new tribometer device. Lubr. Sci. 21, 253-268 (2009). https://doi.org/10.1002/ls.88 
25. Heyer, P., Läuger, J.: a flexible platform for tribological measurements on a rheometer. AIP Conf. Proc. (2008). https://doi.org/10. $1063 / 1.2964504$

26. Läuger, J., Pondicherry, K.: New insights into the use of a rotational rheometer as tribometer. Annu. Trans. Nord. Rheol. Soc. 25, 333-340 (2017)

27. Anton Paar: Reference Guide, T-PID/44, Pin-on-Disk Tribology Accessory with an additional information package [internal pdfdocument]. https://www.anton-paar.com/corp-en/services-suppo rt/document-finder/(2019)

28. Goh, S.M., Versluis, P., Appelqvist, I.A.M., Bialek, L.: Tribological measurements of foods using a rheometer. Food Res. Int. 43, 183-186 (2010). https://doi.org/10.1016/j.foodres.2009.09.024

29. Nguyen, P.T.M., Bhandari, B., Prakash, S.: Tribological method to measure lubricating properties of dairy products. J. Food Eng. 168, 27-34 (2016). https://doi.org/10.1016/j.jfoodeng.2015.07. 011

30. Gallego, R., Cidade, T., Sánchez, R., Valencia, C., Franco, J.M.: Tribological behaviour of novel chemically modified biopolymerthickened lubricating greases investigated in a steel-steel rotating ball-on-three plates tribology cell. Tribol. Int. 94, 652-660 (2016). https://doi.org/10.1016/j.triboint.2015.10.028

31. Bhushan, B.: Introduction to Tribology. Wiley, New York (2013)

32. Jourani, A., Bouvier, S.: Friction and wear mechanisms of $316 \mathrm{~L}$ stainless steel in dry sliding contact: effect of abrasive particle size. Tribol. Trans. 58, 131-139 (2015). https://doi.org/10.1080/ 10402004.2014.955229
33. Kumar, N., Gautam, G., Gautam, R.K., Mohan, A., Mohan, S.: Wear, friction and profilometer studies of insitu AA5052/ZrB2 composites. Tribol. Int. 97, 313-326 (2016). https://doi.org/10. 1016/j.triboint.2016.01.036

34. Kavehpour, H.P., McKinley, G.H.: Tribo-rheometry: from gapdependent rheology to tribology. Tribol. Lett. 17, 327-335 (2004). https://doi.org/10.1023/B:TRIL.0000032471.06795.ea

35. Misra, A., Finnie, I.: Some observations on two-body abrasive wear. Wear 68, 41-56 (1981). https://doi.org/10.1016/00431648(81)90018-1

36. Date, S.W., Malkin, S.: Effects of grit size on abrasion with coated abrasives. Wear 40, 223-235 (1976). https://doi.org/10.1016/ 0043-1648(76)90100-9

37. Rabinowicz, E., Mutis, A.: Effect of abrasive particle size om wear. Wear (1965). https://doi.org/10.1016/0043-1648(65) 90169-9

38. Gammelgård, A.: Slipprocessens mekanismer-utvärdering med hjälp av tribologicell. Master's thesis [swe], Energy Technology, Åbo Akademi University, Vasa. (2018)

Publisher's Note Springer Nature remains neutral with regard to jurisdictional claims in published maps and institutional affiliations. 